\title{
PEMODELAN INVERSI DATA MAGNETOTELLURIK 1-D MENGGUNAKAN METODA GENETIC ALGORITHM (GA) DENGAN POPULASI MICRO GENETIC ALGORITHM KASUS 3 LAYER DAN 5 LAYER
}

\author{
Nia Maharani \\ Email:niamaharani2018@gmail.com
}

\begin{abstract}
ABSTRAK
Makalah ini membahas metoda inversi non-linier menggunakan metoda Genetic Algorithm (GA) yang diinspirasikan oleh proses seleksi alam (survival for the fittest) dan genetika menggunakan 20 populasi (micro genetic algorithm). Metoda tersebut diaplikasikan pada inversi data magnetotellurik 1-D dengan parameter model adalah resistivitas sebagai fungsi dari kedalaman. Penelitian ini hanya menggunakan data sintetik yang didapat dari model sintetik. Model sintetik yang digunakan adalah model bumi homogen 3 layer dan 5 layer. Pertubasi model dilakukan hingga dicapai misfit minimum antara data teoritik dan data pengamatan. Proses inversi tiga lapis diterapkan pada model bumi 3 layer dan inversi lima lapis pada model bumi 5 layer dengan hasil yang cukup memuaskan dengan kata lain dapat mereproduksi kembali model sintetik.
\end{abstract}

Kata kunci : inversi, magnetotellurik 1-D

\begin{abstract}
This paper discusses non-linear inversion method with Genetic Algorithm (GA) which inspired by natural selection process (survival for the fittest) and genetic using 20 populations (micro genetic algorithm). The method is applied to 1-D magnetotelluric inverted data with model parameter is resistivity as a function of depth. This research only uses synthetic data obtained from synthetic model. The model is homogeneous earth model with 3 and 5 layers. Perturbation of model is performed until minimum misfit between theoritical and observation data achieved. The 3 layers and 5 layers inversion processes are applied to 3 layers and 5 layers earth model respectively, with satisfactory results in other words it can reproduce the synthetic model.
\end{abstract}

Keywords: Inversion, 1-D Magnetotelluric 


\section{PENDAHULUAN}

Proses inversi bertujuan untuk mendapatkan model optimal yang dilakukan dengan cara mencari nilai minimum suatu fungsi obyektif. Fungsi tersebut menggambarkan perbedaan antara data teoritik sebagai respons model yang diberikan dengan data observasi.

Pada kasus magnetotellurik (MT) 1 dimensi, resistivitas hanya bervariasi terhadap kedalaman sehingga model dapat direpresentasikan oleh lapisan-lapisan horisontal dengan parameter model adalah resistivitas dan ketebalan tiap-tiap lapisan. Terdapat banyak metoda inversi dalam mencari solusi yang optimum, salah satunya adalah pendekatan linier. Penggunaan metoda tersebut kurang memadai untuk kasus MT dengan alasan meskipun pemodelan MT 1-D relatif sederhana namun hubungan antara data dan parameter model sangat tidak linier (highly non-linear). Jika model awal tidak tepat maka solusi konvergen kemungkinan menuju minimum lokal bukan minimun global yang merupakan solusi yang diharapkan (optimal).

Untuk mengatasi problem tersebut maka dilakukan optimasi secara menyeluruh (global) untuk mencari nilai minimum suatu fungsi obyektif non-linier. Ruang model dimana terdapat solusi (model) yang dicari didefinisikan oleh batas minimum dan maksimum harga setiap parameter model. Pencarian minimum fungsi obyektif pada ruang tersebut dilakukan secara acak (random) menggunakan metoda Genetic Algorithm (GA).

\section{METODA PENELITIAN}

Penelitian ini hanya menggunakan model sintetik tiga lapisan dan lima lapisan, Proses inversi menggunakan metoda GA dilakukan untuk tiga lapis pada model tiga layer dan inversi lima lapis untuk model lima layer.

\section{Algoritma Genetik}

Metoda algoritma genetik adalah salah satu teknik optimasi global yang diinspirasikan oleh proses seleksi alam untuk menghasilkan individu atau solusi yang lebih baik (survival for the fittest) dan genetika (Goldberg, 1989). Metoda tersebut pertama kali dikembangkan oleh John Holland pada pertengahan tahun 1970. Metoda algoritma genetik juga merupakan perkembangan dari evolutionary algorithm yang hanya menggunakan prinsip seleksi dan mutasi, sedangkan GA menggunakan prinsip seleksi, cross-over dan mutasi serta beberapa variasi mekanisme yang diinspirasikan oleh alam. Metoda tersebut termasuk kedalam kelompok guided random search.

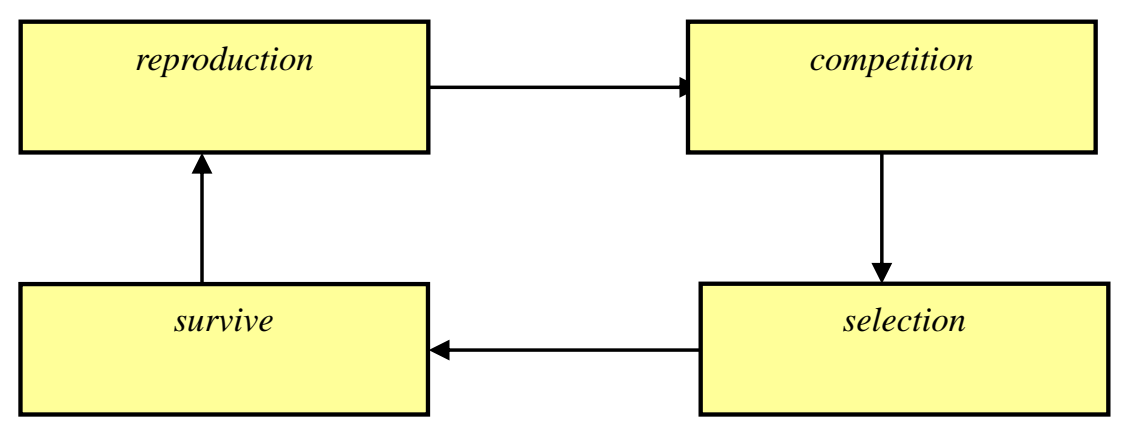

Gambar 1. Bagan siklus seleksi alam (survival for the fittest). 


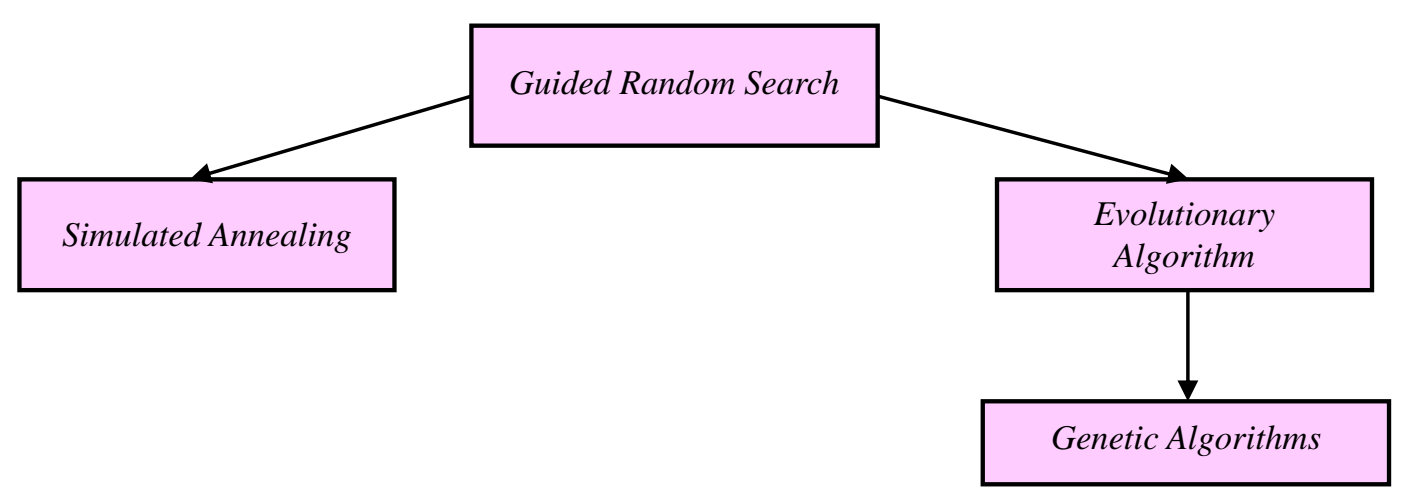

Gambar 1. Teknik pencarian fungsi obyektif non-linier.

Tabel 1. Istilah-istilah dalam seleksi alam dan algoritma genetik

\begin{tabular}{ll}
\multicolumn{1}{c}{$\begin{array}{c}\text { Istilah-istilah } \\
\text { seleksi alam }\end{array}$} & \multicolumn{1}{c}{$\begin{array}{c}\text { Istilah-istilah algoritma } \\
\text { genetik }\end{array}$} \\
kromosom & string (parameter model) \\
\hline gene & karakteristik didalam string \\
\hline locus & posisi didalam string \\
\hline allela & nilai dari string (0 dan 1) \\
\hline genotype & struktur string \\
\hline phenotype & karakteristik genotype \\
\hline populasi & ruang model \\
\hline individu & model \\
\hline kromosom terbaik & model terbaik \\
\hline tingkat adaptasi & error minimum \\
kromosom & \\
\hline generasi & iterasi \\
\hline
\end{tabular}

\section{Karakteristik Algoritma Genetik}

Sebagai salah satu teknik optimasi global dalam pencarian nilai minimum fungsi obyektif non-linier, GA memiliki karakteristik-karakteristik yaitu :

1. GA bekerja dengan suatu kumpulan parameter model yang dicirikan dengan adanya suatu kode (biasanya digunakan kode string).

2. GA mencari solusi dari suatu populasi (sampel ruang model) yang terdiri dari sekumpulan individu secara bersamaan (paralel) bukan dari satu individu (model).

3. GA menggunakan informasi yang berasal dari suatu nilai fungsi obyektif bukan dari turunan / gradien fungsi obyektif sehingga solusi yang diperoleh konvergen menuju minimum global bukan minimum lokal.

4. GA menggunakan probabilistik dalam pencarian solusi bukan deterministik.

5. Sistem GA memiliki kompleksitas yang tinggi.

6. GA memiliki strategi didalam pencarian solusi optimum yang disebut Multimodal Optimization yang ditunjukkan seperti gambar berikut ini :

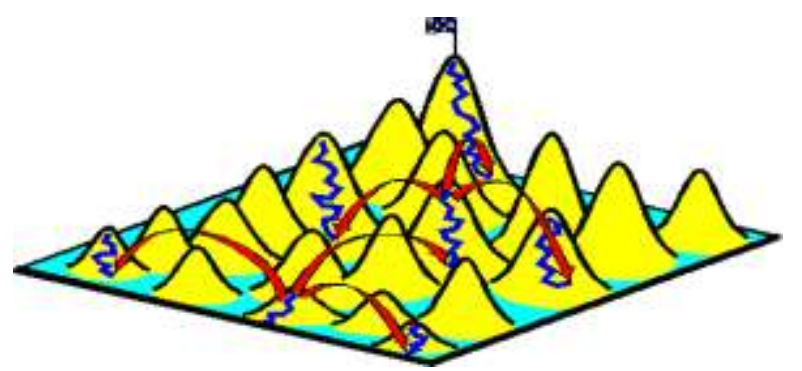

Gambar 2. Strategi pencarian solusi algoritma genetik. 


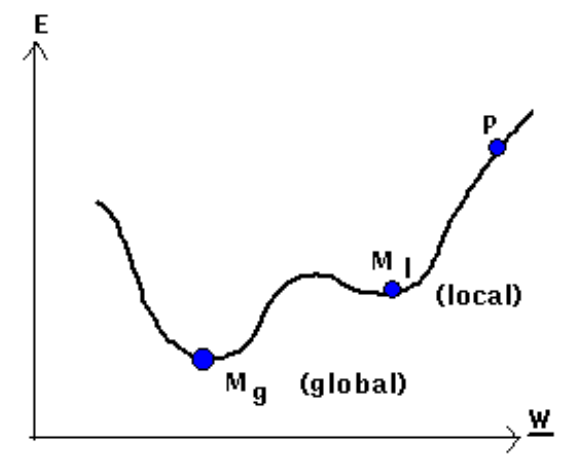

Gambar 3. Fungsi obyektif dengan lebih dari satu nilai minimum.

\section{Proses Algoritma Genetik}

Adapun tahap-tahap algoritma genetik untuk memperoleh suatu turunan atau solusi yang optimum adalah :

\section{Inisialisasi populasi}

Sebagai proses awal maka dibangun suatu populasi (ruang model) yang terdiri dari sekumpulan individu (model) secara acak (random). Populasi ini dapat dikategorikan menjadi dua yaitu :

1. Micro Genetic Algorithm dimana ukuran populasi kecil yaitu berkisar dari 5 hingga 50 populasi (Yubo, Jian \& Fei, 2005).
2. Macro Genetic Algorithm yaitu ukuran populasi berkisar dari 50 hingga 100 populasi (Yubo, Jian \& Fei, 2005).

Sekumpulan individu dalam suatu populasi biasanya dikodekan sebagai bilangan biner sehingga dapat digambarkan sejumlah bit (binary digit) yang menunjukkan posisi tiap angka, terdiri dari angka 0 dan 1. Dalam algoritma genetik anggota suatu populasi dipilih berdasarkan fitness-nya dan jumlah populasi dalam suatu generasi dibuat tetap.

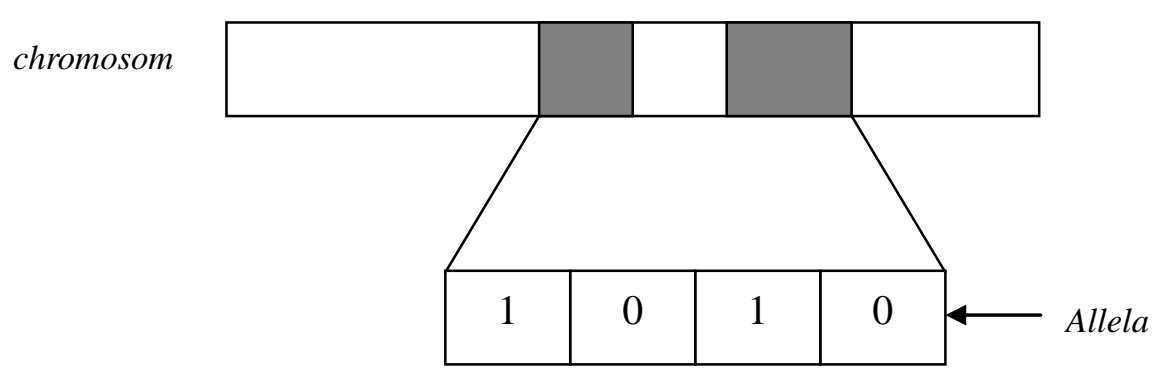

Gambar 4. Struktur kromosom (parameter model).

\section{Decoding}

Setelah dibangun suatu populasi dalam bilangan biner, maka langkah selanjutnya adalah mengkonversi bilangan biner ke bilangan riil. Dalam proses ini tidak hanya sekedar mengkonversi bilangan biner ke riil saja tapi disesuaikan dengan interval suatu harga parameter model yang diinginkan.
Misalkan suatu bilangan biner, $\mathrm{x}$ dengan panjang bit, $\mathrm{m}$ lalu ingin dipetakan kedalam suatu interval $[a, b]$, sehingga :

$$
x=a+\operatorname{desimal}(x)\left(\frac{b-a}{2^{m}-1}\right)
$$


Contoh : $\mathrm{x}=011$ dengan panjang bit, $\mathrm{m}=3$, desimal $(x)=3$ ingin dikonversi ke bilangan riil dalam suatu interval $[10,20]$, sehingga :

$$
x=10+3\left(\frac{20-10}{2^{3}-1}\right)=14,26
$$

Dari hasil tersebut jelas bahwa hasil konversi berada dalam interval [10,20].

\section{Evaluasi Fitness}

Setiap individu dalam suatu populasi merupakan kandidat untuk suatu solusi optimum. Nilai fitness dari tiap-tiap individu menggambarkan seberapa besar peluang suatu individu dalam suatu generasi untuk dapat bertahan pada generasi berikutnya. Dalam hal inversi, fitness

Tahap-tahap seleksi menggunakan RouletteWheel adalah sebagai berikut :

1. Evaluasi fitness, $\mathrm{f}_{i}$, masing-masing individu dalam suatu populasi.

2. Menghitung probabilitas, $\mathrm{p}_{i}$, tiap-tiap individu.

$$
\mathrm{p}_{i}=\frac{\mathrm{f}_{i}}{\sum_{j=1}^{n} \mathrm{f}_{j}}
$$

dimana $\mathrm{n}$ adalah ukuran populasi dan $\mathrm{f}_{j}$ adalah fitness kumulatif/total.

3. Lalu menghitung probabilitas kumulatif tiap-tiap individu, $\mathrm{q}_{i}$

$$
\mathrm{q}_{i}=\sum_{j=1}^{i} \mathrm{p}_{j}
$$

4. Bangkitkan suatu bilangan acak (random), $r \in[0,1]$. dinyatakan oleh kesesuaian antara data dan parameter model.

\section{Reproduksi}

Peluang suatu individu untuk dapat bertahan dari suatu generasi ke generasi berikutnya bergantung pada fitness individu tersebut. Individu dengan fitness yang cukup besar memiliki kemungkinan yang lebih besar untuk dapat bereproduksi. Proses seleksi pada dasarnya adalah memilih individu-individu dengan harga fitness yang tinggi dari suatu populasi untuk bereproduksi (menghasilkan turunan). Pada penelitian ini dilakukan teknik seleksi Roulette-Wheel (Proportional Fitness). Fitness terbaik akan memiliki nilai sama dengan 1.

5. Jika $\mathrm{r}<\mathrm{q}_{i}$, maka yang dipilih adalah individu pertama, $\mathrm{x}_{1}$. Jika $\mathrm{q}_{i-1}<\mathrm{r}<\mathrm{q}_{i}$ maka pilih individu $\mathrm{x}_{i}$.

6. Langkah 4 - 5 diulang sebanyak ukuran populasi untuk memperoleh individuindividu yang nantinya akan bereproduksi.

Tiap individu yang baik akan mengambil bagian yang lebih besar dibandingkan dengan individu yang memiliki fitness yang kecil dan kemungkinan lebih besar untuk dipilih.. Prinsip seleksi tersebut sesuai dengan survival for the fittest.

\section{Cross-Over}

Cross-over merupakan salah satu operator genetik yang digunakan untuk menggabungkan dua genetik dari sepasang induk dalam suatu generasi. Proses ini identik dengan reproduksi seksual dalam kehidupan. Dalam proses ini sepasang induk dipilih berdasarkan fitness-nya dan turunan (offspring) merupakan hasil 
penyilangan karakteristik atau parameter induk yang dipilih secara acak. Probabilitas cross-over bernilai 0,4 sampai 0,8 (Coley, 1998). Dalam hal inversi proses penyilangan ini merepresentasikan kerja sama individu untuk sampai pada titik lain dalam sampel ruang model secara langsung tanpa melalui pertubasi sedikit demi sedikit. Beberapa teknik cross-over adalah :

1. Single point cross-over

Pada teknik ini dibangkitkan suatu bilangan acak yang menunjukkan posisi bit tempat terjadinya kawin silang. Anak1 pada bagian depan mengandung kromosom yang disumbangkan oleh induk-1 dan bagian belakang berisi kromosom yang disumbangkan oleh induk-2. Begitu pula dengan anak-2, pada bagian depan berisi kromosom yang disumbangkan oleh induk-2 dan bagian belakang berisi kromosom yang disumbagkan oleh induk-1. Proses single-point cross-over ditampilkan sebagai berikut :

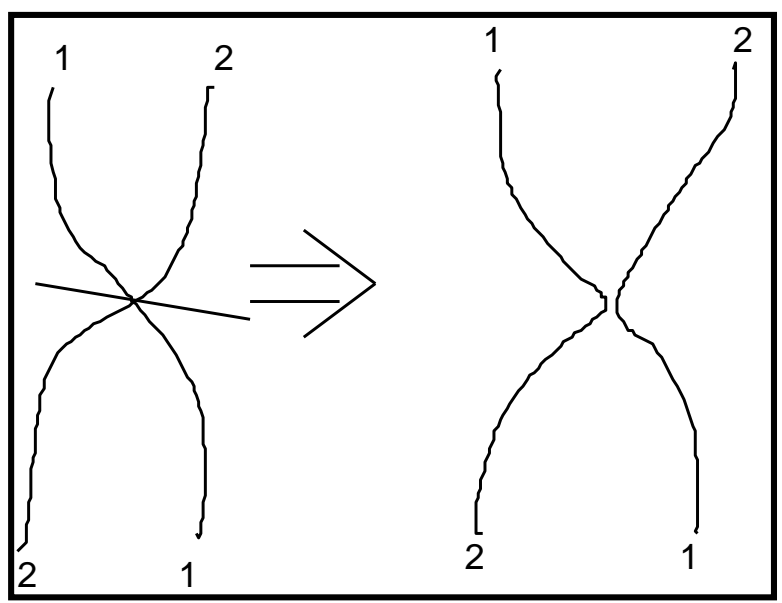

Gambar 5. Teknik single point cross-over.

\section{Multi point cross-over}

Pada penelitian ini digunakan teknik multi-point cross-over atau one-point cross-over tiap-tiap parameter. Caranya adalah dengan membangkitkan bilangan acak yang menunjukkan posisi bit pada kromosom induk sebanyak n-parameter. Turunannya (offspring) adalah terdiri dari anak-1 yang berisi kromosom yang disumbangkan oleh parameter-n induk-1 bagian depan dan kromosom yang disumbangkan oleh parameter-n induk-2 bagian belakang. Sedangkan anak-2 berisi kromosom parameter-n induk-2 bagian depan dan kromosom parameter-n induk-1 bagian belakang . Proses tersebut diulangi sampai n-parameter. Proses cross-over dapat dijelaskan seperti gambar dibawah ini, tanda panah menunjukkan posisi bit terjadinya crossover tiap-tiap parameter model. Masingmasing induk terdiri dari n-parameter model (par-1 sampai par-n). 


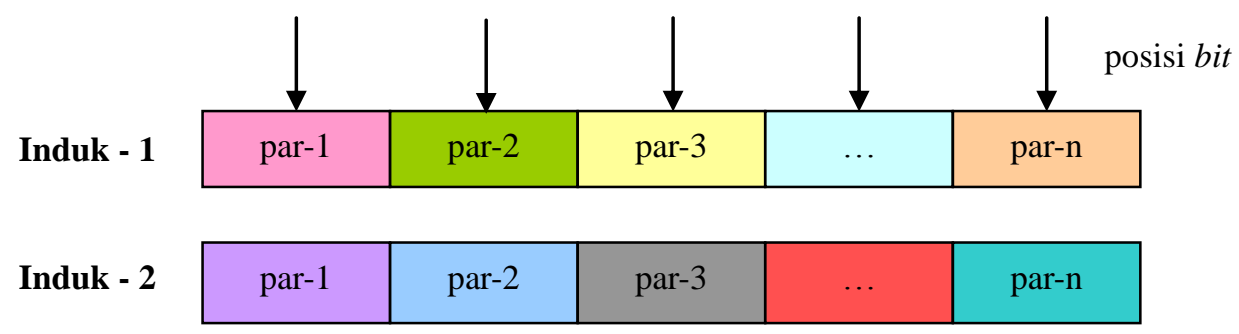

Detail proses one-point cross-over

parameter-1 ditampilkan seperti berikut:

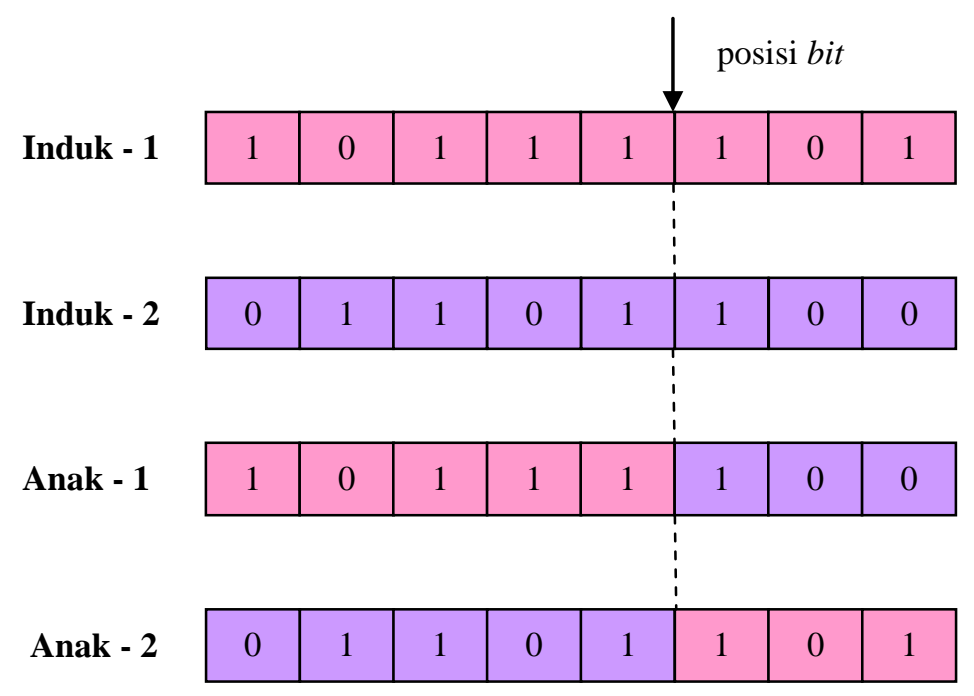

Gambar 7. Proses one-point cross-over parameter ke-n.

6. Mutasi

atau

Dalam proses seleksi alam, mutasi merupakan proses acak dimana suatu allela dari suatu gen atau kromosom akan diganti dengan yang lainnya. Sedangkan dalam algoritma genetik mutasi merupakan proses dimana suatu parameter induk dapat berubah secara acak agar dapat diperoleh individu yang lebih baik dengan menggunakan probabilitas acak yang kecil, biasanya bernilai 0,001-0,1 (Coley, 1998).

$$
\mathrm{P}_{\mathrm{m}}=\frac{1}{\mathrm{~N}(\mathrm{~L})^{\frac{1}{2}}}
$$

dimana $\mathrm{N}$ adalah ukuran populasi dan $\mathrm{L}$ adalah panjang bit (bit length).

Proses ini juga berguna untuk mencegah terjadinya premature convergence dari minimum lokal (Peréz-Florez \& Schultz, 2002).

Pada umumnya probabilitas mutasi $\left(\mathrm{P}_{\mathrm{m}}\right)$ dapat diperoleh juga menggunakan rumusan sebagai berikut :

$$
\mathrm{P}_{\mathrm{m}}=\frac{1}{\mathrm{~L}}
$$


individu dan akan dihasilkan individu yang baru disamping itu pencarian solusi akan

\section{Magnetotellurik (MT)}

Prinsip dasar prilaku medan-medan elektromagnetik telah berkembang sejak abad yang lalu. Prinsip tersebut adalah pada saat arus listrik mengalir maka akan timbul medan magnetik disekitarnya. Medan magnetik tersebut apabila berubah terhadap waktu maka medan listrik akan terbentuk. Maxwell pada tahun 1973 merumuskan prinsip tersebut sebagai dasar untuk teori medan-medan elektromagnetik. Dasar dari metoda elektromagnetik adalah bahwa variasi medan elektromagnetik bumi tidak hanya bergantung pada kekuatan dan karakteristik sumber menuju kepada metoda random (acak).

medan, tetapi juga fungsi dari dari sifat kelistrikan (konduktivitas) bumi. Salah satu metoda geofisika yang tergolong ke dalam metoda elektromagnetik adalah metoda magnetotellurik (MT) yang menggunakan sumber medan elektromagnetik alam. Medan elektromagnetik alam dapat ditimbulkan oleh interaksi antara partikel yang dipancarkan matahari dengan medan magnet permanen bumi dengan frekuensi kurang dari 1 Hertz. Sedangkan medan elektromagnet yang diakibatkan oleh aktifitas petir memiliki frekuensi diatas 1 Hertz.

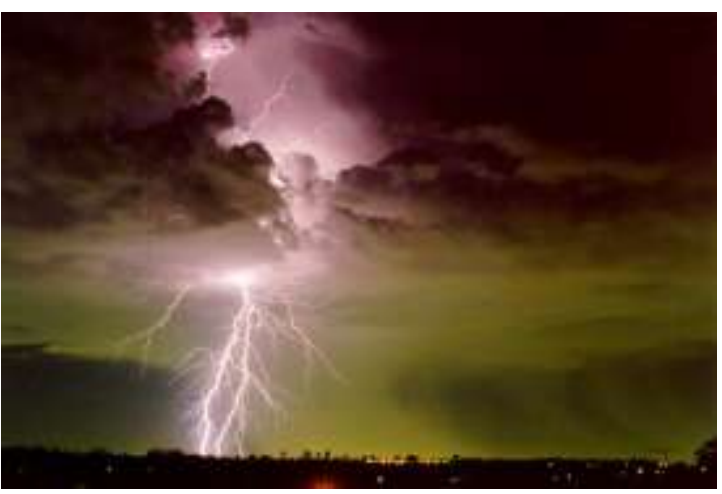

Gambar 8. Medan elektromagnet yang diakibatkan oleh petir (sumber : www.google.com)

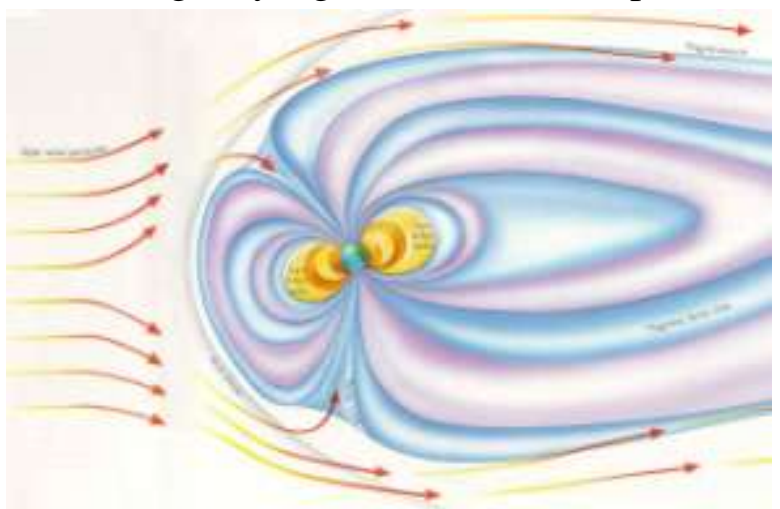

Gambar 9. Medan elektromagnet yang disebabkan oleh interaksi antara partikel yang dipancarkan matahari dengan medan magnet sumber (www.google.com)

Konsep dasar metoda magnetotellurik adalah mencari informasi kondisi bawah permukaan dengan mengukur komponen tangensial (horisontal) dari medan listrik dan medan magnetik pada suatu titik observasi dengan memanfaatkan sumber-sumber medan elektromagnetik yang telah disebutkan diatas. Dari komponen-komponen tersebut ditentukan perbandingan intensitas medan listrik terhadap medan magnetik yang disebut impedansi listrik (fungsi dari sifat listrik medium). Rumusan matematis impedansi adalah : 


$$
\mathrm{Z}_{\alpha \beta}=\frac{\mathrm{E}_{\alpha}}{\mathrm{H}_{\beta}}
$$

dimana $\mathrm{E}_{\alpha}$ dan $\mathrm{H}_{\beta}$ selalu saling tegak lurus untuk medium berlapis horisontal. Dengan menentukan impedansi pada sederet frekuensi yang berurutan maka diperoleh informasi mengenai sebaran konduktivitas listrik sebagai fungsi dari kedalaman. Skin depth atau kedalaman penetrasi gelombang elektromagnetik menyatakan daya jangkau gelombang elektromagnet. Semakin kecil frekuensinya maka semakin besar kedalaman penetrasi gelombang EM sehingga akan diperoleh informasi kondisi dari lapisan yang paling dalam.

\section{Konsep Umum Medan Elektromagnetik}

Penurunan rumus impedansi menggunakan asumsi bahwa gelombang elektromagnetik (EM) diperlakukan sebagai gelombang bidang yaitu gelombang hanya berubah dalam arah penjalaran gelombang dan konstan pada bidang yang tegak lurus arah penjalaran.

Prilaku medan elektromagnetik didasarkan pada persamaan Maxwell pada medium homogen isotropis. Persamaan tersebut dapat dinyatakan dalam bentuk diferensial sebagai berikut :

$$
\begin{gathered}
\nabla \times \mathbf{E}=\frac{\partial \mathbf{B}}{\partial \boldsymbol{t}} \\
\nabla \times \mathbf{H}=\mathbf{j}+\frac{\partial \mathbf{D}}{\partial \boldsymbol{t}} \\
\nabla . \mathbf{D}=\mathrm{q} \\
\nabla . \mathbf{B}=0
\end{gathered}
$$

dimana: $\mathbf{H}=$ medan magnet dalam Ampere/m

$\mathbf{B}=$ induksi magnet dalam $\mathrm{Weber} / \mathrm{m}^{2}$ atau Tesla

$\mathrm{q}$ = rapat muatan dalam Coulumb $/ \mathrm{m}^{3}$

$\mathbf{D}=$ perpindahan listrik dalam Coulumb $/ \mathrm{m}^{2}$

$\mathbf{E}=$ medan listrik dalam Volt $/ \mathrm{m}$

$\mathbf{j}=$ rapat arus dalam Ampere $/ \mathrm{m}^{2}$
Hubungan antara medan elektromagnetik dan sifat fisik medium dinyatakan oleh :

$$
\begin{gathered}
\mathbf{B}=\mu \mathbf{H} \\
\mathbf{D}=\varepsilon \mathbf{E} \\
\mathbf{j}=\sigma \mathbf{E}
\end{gathered}
$$

dimana: $\mu=$ permeabilitas magnetik dalam Henry/m

$\varepsilon=$ permitivitas listrik dalam Farad $/ \mathrm{m}$ $\sigma=$ konduktivitas listrik dalam Siemens/m atau (Ohm.m) ${ }^{-1}$

Dengan mensubtisusikan ketiga hubungan tersebut dan menerapkannya pada medium homogen isotropik dimana $\varepsilon, \sigma$ dan $\mu$ konstan terhadap ruang dan waktu, maka persamaan Maxwell dapat dituliskan sebagai berikut :

$$
\begin{gathered}
\nabla \times \mathbf{E}=-\mu \frac{\partial \mathbf{H}}{\partial t} \\
\nabla \times \mathbf{H}=\sigma \mathbf{E}+\varepsilon \frac{\partial \mathbf{E}}{\partial t} \\
\nabla . \mathbf{E}=0 \\
\nabla . \mathbf{H}=0
\end{gathered}
$$

Pada persamaan keempat dari persamaan diatas $\mathrm{q}=0$, karena pada medium homogen tidak terdapat muatan bebas. Dalam masalah kelistrikan, persamaan Maxwell perlu dipisahkan variabel-variabelnya yaitu dengan melakukan operasi curl terhadap variabel medan listrik $\mathrm{E}$ dan medan magnet $\mathrm{H}$ pada persamaan tersebut, sehingga diperoleh :

$$
\begin{aligned}
& \nabla \times \nabla \times \mathbf{E}=-\mu \sigma \frac{\partial \mathbf{E}}{\partial \boldsymbol{t}}-\mu \varepsilon \frac{\partial^{2} \mathbf{E}}{\partial t^{2}} \\
& \nabla \times \nabla \times \mathbf{H}=-\mu \sigma \frac{\partial \mathbf{H}}{\partial \boldsymbol{t}}-\mu \varepsilon \frac{\partial^{2} \mathbf{H}}{\partial t^{2}}
\end{aligned}
$$

Dengan menggunakan vektor identitas $\nabla \times \nabla$ $\mathrm{x} \mathbf{G}=\operatorname{grad}(\nabla . \mathbf{G})-\nabla^{2} \mathbf{G}$, dimana $\mathbf{G}$ adalah $\mathrm{E}$ atau $\mathrm{H}$ dan hubungan yang dinyatakan dalam persamaan (11) dan (12) maka didapatkan persamaan Helmholtz yang menggambarkan prilaku medan EM sebagai berikut :

$$
\begin{aligned}
\nabla^{2} \mathbf{E} & =\mu \sigma \frac{\partial \mathbf{E}}{\partial \boldsymbol{t}}+\mu \varepsilon \frac{\partial^{2} \mathbf{E}}{\partial t^{2}} \\
& =\left(i \omega \mu \sigma-\omega^{2} \mu \varepsilon\right) \mathbf{E}
\end{aligned}
$$




$$
\begin{aligned}
& =k^{2} \mathbf{E} \\
\nabla^{2} \mathbf{H} & =\mu \sigma \frac{\partial \mathbf{H}}{\partial \boldsymbol{t}}+\mu \varepsilon \frac{\partial^{2} \mathbf{H}}{\partial t^{2}} \\
& =\left(i \omega \mu \sigma-\omega^{2} \mu \varepsilon\right) \mathbf{H} \\
& =k^{2} \mathbf{H}
\end{aligned}
$$

dimana $k$ adalah bilangan gelombang. Kondisi ini berlaku jika suku yang mengandung $\varepsilon$ diabaikan dengan asumsi untuk kasus MT yaitu permeabilitas magnetik sama dengan permeabilitas magnetik hampa udara $\left(\mu=\mu_{0}=\right.$ $4 \pi \cdot 10^{-7}$ ) sehingga :

$$
\begin{gathered}
k= \pm\left(i \omega \mu_{0} \sigma\right)^{\frac{1}{2}}= \pm(\alpha+i \beta) \\
\alpha=\beta=\left(\frac{\omega \mu_{0}}{2 \rho}\right)
\end{gathered}
$$

Karena bumi diasumsikan homogen dan gelombang bidang EM merambat melalui medium tersebut, maka komponen medan listrik dan medan magnet tidak berubah sepanjang bidang horisontal. Dengan demikian persamaan Helmholtz dapat dituliskan menjadi

$$
\frac{\partial^{2} \mathbf{E}_{\chi}}{\partial z^{2}}=k^{2} \mathbf{E}_{x}
$$

Solusi elementer dari persamaan tersebut adalah :

$$
\begin{gathered}
\mathbf{E}_{\mathbf{x}}=A \mathrm{e}^{-k z}+B \mathrm{e}^{+k z} \\
\mathbf{E}_{\mathbf{x}}=A \mathrm{e}^{-i \alpha z} \mathrm{e}^{-\beta z}+B \mathrm{e}^{+i \alpha z} \mathrm{e}^{+\beta z}
\end{gathered}
$$

dimana $x, y$ dan $z$ adalah sumbu koordinat kartesian dengan $z$ adalah kedalaman (positif vertikal ke bawah). Secara umum eksponensial yang mengandung komponen bilangan imajiner dari $k\left(\mathrm{e}^{ \pm i \alpha z}\right)$ menyatakan variasi sinusoidal gelombang EM terhadap kedalaman, sedangkan eksponensial yang mengandung bilangan riil dari $k\left(\mathrm{e}^{ \pm} \beta \quad z\right)$ menyatakan faktor atenuasi menurut sumbu $\mathrm{z}$ positif atau $\mathrm{z}$ negatif. Konstanta $A$ dan $B$ ditentukan berdasarkan syarat batas. Dekomposisi persamaan (9), dengan memperhatikan hubungan (22), menghasilkan komponen medan magnet sebagai berikut :

$$
\begin{gathered}
\mathbf{H}_{\mathbf{y}}=-\frac{1}{i \omega \mu_{0}} \frac{\partial \mathrm{E}_{\mathrm{x}}}{\partial z}=\frac{k}{i \omega \mu_{0}}\left(A \mathrm{e}^{-k z}-B \mathrm{e}^{+k z}\right) \\
\mathrm{Z}_{\mathrm{xy}}=\frac{\mathrm{E}_{\mathrm{x}}}{\mathrm{H}_{\mathrm{y}}}=\left(i \omega \mu_{0}\right)^{\frac{1}{2}}
\end{gathered}
$$

\section{Impedansi Medium Berlapis Horisontal}

Perhitungan impedansi yang sederhana untuk kasus medium bumi berlapis horisontal adalah melalui rumus rekursif. Dengan menggunakan impedansi lapisan terakhir berupa medium homogen yang bernilai 1 maka dapat dihitung impedansi lapisan diatasnya sampai impedansi permukaan bumi. Impedansi diasumsikan sebagai koefisien reflektifitas (Zhdanov \& Keller, 1998). Hasilnya digunakan untuk membangun suatu forward modelling.

Koefisien reflektifitas lapisan berikutnya $\mathrm{j}\left(\mathrm{R}_{2}\right)$ sampai permukaan bumi $\left(\mathrm{R}_{\mathrm{N}}\right)$ :

$$
\mathrm{R}(\mathrm{j})=\frac{1-\mathrm{K}(\mathrm{j}) \mathrm{e}^{(-2 i \mathrm{kud}(\mathrm{N}-\mathrm{j}+1)}}{1+\mathrm{K}(\mathrm{j}) \mathrm{e}^{(-2 i \mathrm{kud}(\mathrm{N}-\mathrm{j}+1)}}
$$

dimana :

$$
\begin{aligned}
& \mathrm{K}(\mathrm{j})=\frac{1-\frac{\mathrm{ku}}{\mathrm{kl}} \mathbf{R}(\mathbf{j}-1)}{1+\frac{\mathrm{ku}}{\mathrm{kl}} \mathrm{R}(\mathbf{j}-1)} \\
& \mathrm{ku}=\left[i \omega \mu_{0} \sigma(\mathrm{N}-\mathrm{j}+1)\right]^{\frac{1}{2}} \\
& \mathrm{kl}=\left[i \omega \mu_{0} \sigma(\mathrm{N}-\mathrm{j}+2)\right]^{\frac{1}{2}}
\end{aligned}
$$

dimana $\mathrm{d}$ adalah ketebalan lapisan dan $\mathrm{N}$ adalah banyaknya lapisan bumi serta $i$ adalah bilangan imajiner.

Untuk medium berlapis horisontal maka tahanan jenis yang dihasilkan adalah tahanan jenis semu sehingga :

$$
\begin{gathered}
\rho_{\mathrm{a}}=\frac{1}{\omega \mu_{0}}\left|\mathrm{Z}_{\mathrm{I}}\right|^{2} \\
\phi=\tan ^{-1}\left[\frac{\operatorname{lm} Z_{\mathrm{I}}}{\operatorname{Re} Z_{\mathrm{I}}}\right]
\end{gathered}
$$


HASIL

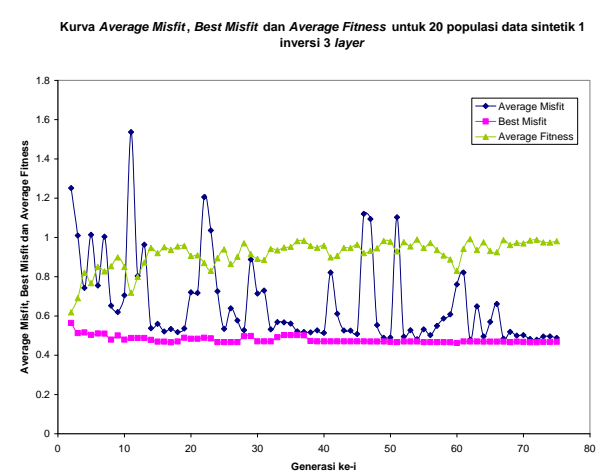

Gambar 10. Kurva Average Misfit, Best Misfit dan Average Fitness inversi tiga layer 20 sampel ruang model

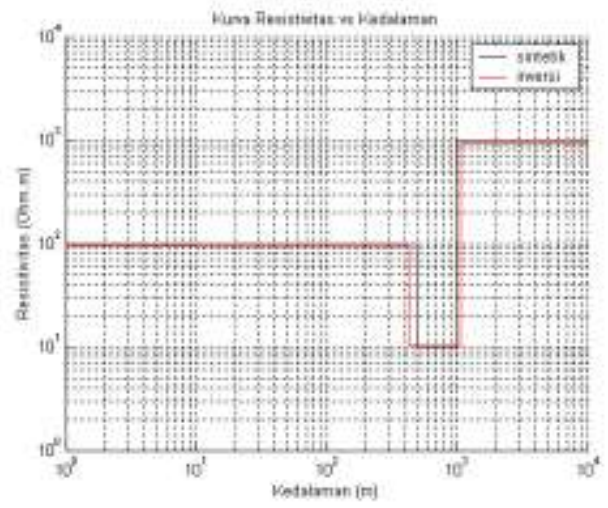

Gambar 11. Model sintetik dan hasil inversi tiga layer 20 sampel ruang model

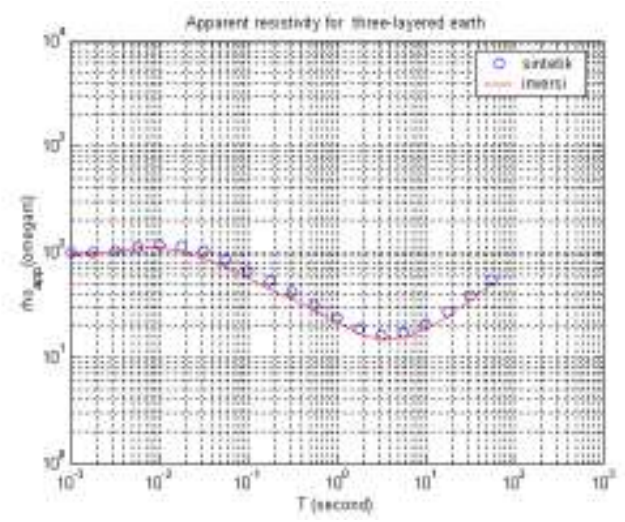

Gambar 12. Resistivitas semu sintetik dan hasil inversi tiga layer 20 populasi

\section{Inversi tiga lapis}

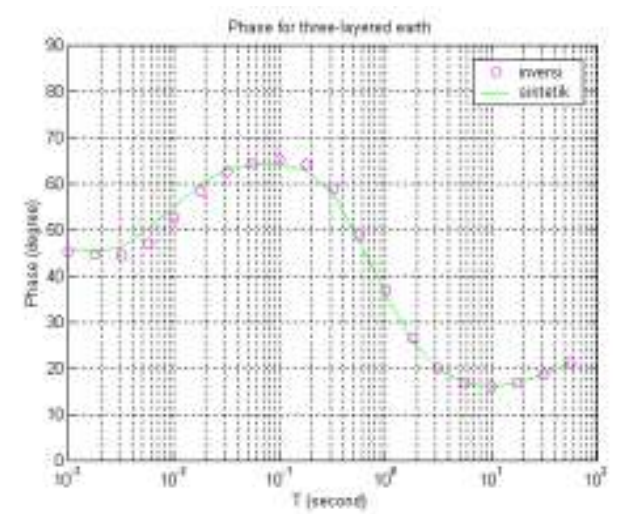

Gambar 13. Fasa sintetik dan hasil inversi tiga layer 20 sampel ruang model

\section{Inversi data lima layer}

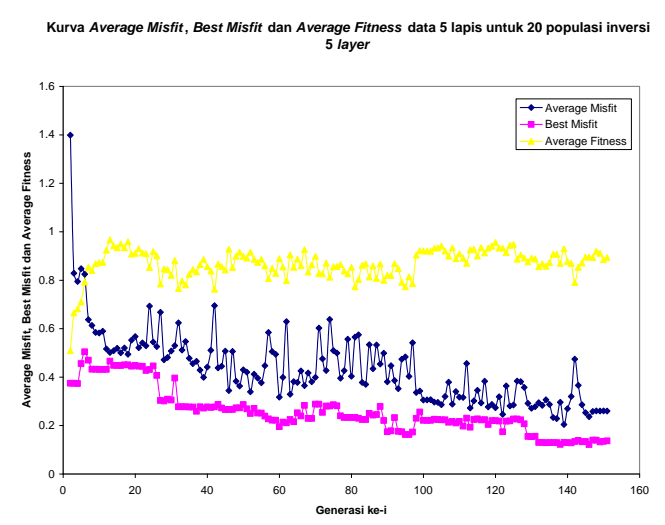

Gambar 14. Kurva Average Misfit, Best Misfit dan Average Fitness inversi lima layer 20 sampel ruang model

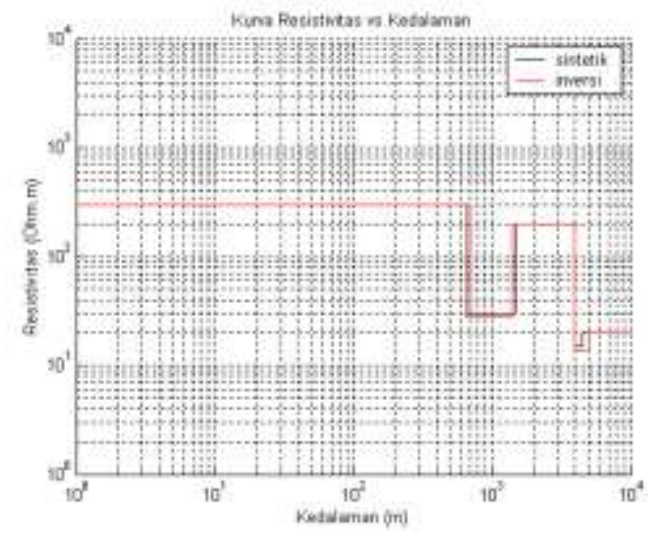

Gambar 15. Model sintetik dan hasil inversi lima layer 20 sampel ruang model 


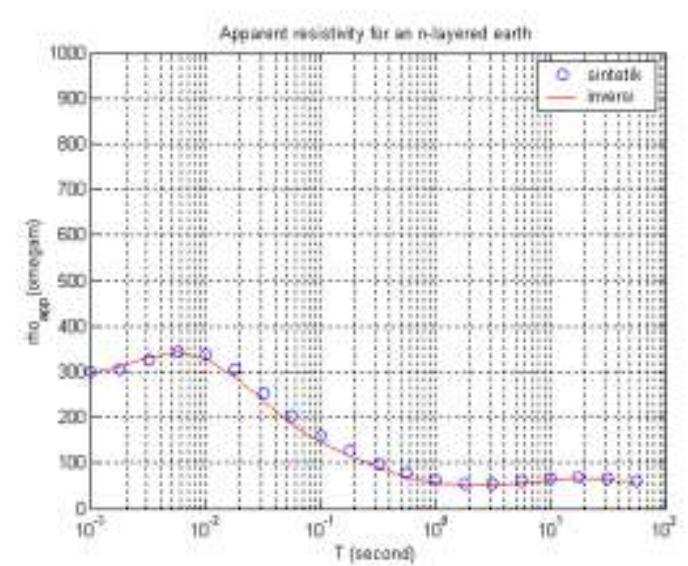

Gambar 16. Resistivitas semu sintetik dan hasil inversi tiga layer 20 populasi

\section{DISKUSI}

\section{Data}

Dalam penelitian ini digunakan data sintetik berupa resistivitas semu dan fasa yang terdiri dari 20 (micro genetic algorithm) dari 0,001 detik sampai 1000 detik atau dari $1000 \mathrm{~Hz}$ sampai 0,001 Hz.. Data tersebut diperoleh dari model-model sintetik sederhana tiga lapisan dan lima. Tujuannya adalah untuk mengetahui sejauh mana efektivitas metoda algoritma genetik dalam memperoleh kembali model sintetik tersebut melalui inversi data sintetik. Dua model sintetik dengan parameterparameter modelnya ditampilkan pada tabel berikut :

Tabel 2. Model sintetik-1

\begin{tabular}{ccc} 
Lapisan & $\begin{array}{c}\text { Ketebalan } \\
(\mathbf{m})\end{array}$ & $\begin{array}{c}\text { Resistivitas } \\
(\text { Ohm.m) }\end{array}$ \\
\hline 1 & 500 & 100 \\
\hline 2 & 1000 & 10 \\
\hline 3 & - & 1000 \\
\hline
\end{tabular}

Tabel 3. Model sintetik-2

\begin{tabular}{ccc} 
Lapisan & $\begin{array}{c}\text { Ketebalan } \\
(\mathbf{m})\end{array}$ & $\begin{array}{c}\text { Resistivitas } \\
(\mathbf{O h m . m})\end{array}$ \\
\hline 1 & 700 & 300 \\
\hline 2 & 1500 & 30 \\
\hline 3 & 4000 & 200 \\
\hline 4 & 4500 & 15 \\
\hline 5 & - & 20 \\
\hline
\end{tabular}

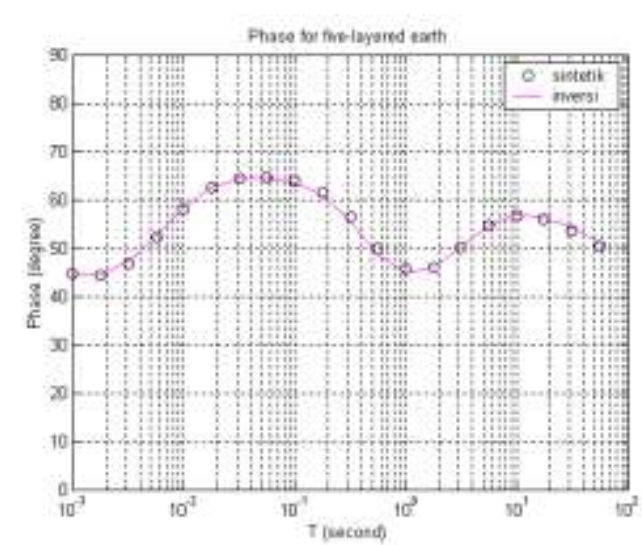

Gambar 17. Fasa sintetik dan hasil inversi lima layer 20 sampel ruang model

\section{Inversi tiga lapis model sintetik-1}

Dalam penelitian ini proses inversi tiga lapis dan lima lapis diterapkan terhadap data sintetik-1 dan data sintetik-2. Parameterparameter yang konstan selama proses-proses inversi tersebut yaitu probabilitas cross-over $(\mathrm{Pc})=0,8$, probabilitas mutasi $(\mathrm{Pm})=0,05$, faktor bobot fasa $(\beta)=1$ dan panjang bit $=10$. Nilai Pc selalu lebih besar dari nilai Pm. Jika diambil nilai Pc kecil maka pada saat proses cross-over semua model akan langsung kekopi untuk diteruskan ke generasi berkutnya. Seperti yang telah dijelaskan pada bab sebelumnya bahwa prinsip cross-over adalah menggabungkan string dari dua model yang berbeda yang berarti mengambil bagian karakteristik (parameter model) yang baik dari dua karakteristik yang berlainan. Dengan harapan akan dihasilkan suatu turunan (solusi) yang terbaik. Pm selalu bernilai kecil karena jika nilainya besar maka akan merusak suatu gen atau dalam hal inversi nilai parameter model dapat berubah secara acak. Diharapkan kode string yang terakhir meupakan solusi yang terbaik dari suatu permasalahan. Pada data sintetik, kualitas fasanya bagus sehingga digunakan faktor bobot fasa $(\beta)=1$ dengan tujuan untuk melihat sejauh mana data fasa 
dapat dikembalikan melalui proses inversi. Beda halnya dengan data lapangan, kualitas fasa biasanya buruk sehingga pada umumnya nilai faktor bobot fasa yang diambil sama dengan 0. Gambar 16 menampilkan kurva misfit rata-rata, misfit terbaik dan fitness ratarata hasil inversi tiga lapis data sintetik-1 yang diperoleh dengan menggunakan 20 sampel ruang model, jumlah generasi (iterasi) 70 sehingga diperoleh misfit terbaik $=0,448$, misfit rata-rata $=0,438$ dan fitness rata-rata $=$ 0,981. Tampak bahwa pola kurva misfit ratarata adalah fluktuatif dan mencapai konvergen pada saat iterasi ke 70. Pola kurva fitness ratarata berlawanan dengan misfit rata-rata serta misfit terbaik karena nilai fitness berbanding terbalik dengan misfit. Semakin besar fitnessnya maka semakin kecil misfit yang diperoleh. Sedangkan dari hasil pemodelan tampak bahwa model inversi dapat merepresentasikan model sintetik resistivitas semu maupun fasa dengan cukup baik meskipun terdapat perbedaan yang disebabkan masalah ekivalensi (gambar 11 dan 12).

\section{Inversi lima lapis model sintetik-2}

Kurva misfit rata-rata, misfit terbaik dan fitness rata-rata hasil inversi lima lapis data sintetik-2 yang diperoleh dengan menggunakan 20 sampel ruang model, jumlah generasi (itearasi) 150 ditampilkan pada gambar 20. Dari hasil running program diperoleh misfit terbaik = 0,448 , misfit rata-rata $=0,260$ dan fitness ratarata $=0,893$. Tampak bahwa pola kurva misfit rata-rata adalah fluktuatif dan mencapai konvergen pada saat iterasi ke 150. Lamanya waktu iterasi inversi tiga lapis pada model tiga lapis lebih cepat bila dibandingkan dengan waktu iterasi model lima lapis. Hal ini disebabkan parameter model yang digunakan lebih banyak pada model lima lapis yaitu 9 parameter model. Sedangkan pada model tiga lapis hanya 5 parameter model. Sedangkan tinjauan dari pola kurva fitness rata-rata memiliki pola yang sama dengan hasil inversi tiga lapis yaitu berlawanan dengan misfit ratarata serta misfit terbaik karena nilai fitness berbanding terbalik dengan misfit. Gambar 16 dan 17 menunjukkan bahwa model inversi lima lapis dapat merepresentasikan model sintetik resistivitas semu maupun fasa dengan cukup baik meskipun ekivalensi masih menjadi faktor ketidakunikan dalam pemodelan MT 1-D.

Tabel 4. Rata-rata Hasil Inversi Tiga Lapisan 20 Model Sintetik-1

\begin{tabular}{ccc}
$\begin{array}{c}\text { Lapisa } \\
\mathbf{n}\end{array}$ & $\begin{array}{c}\text { Resistivitas } \\
(\mathbf{O h m . m})\end{array}$ & $\begin{array}{c}\text { Ketebalan } \\
(\mathbf{m})\end{array}$ \\
\hline 1 & 94,563 & 427,810 \\
\hline 2 & 10,006 & 1060,790 \\
\hline 3 & 927,104 & - \\
\hline
\end{tabular}

Tabel 5. Rata-rata Hasil Inversi Lima Model Sintetik-2

\begin{tabular}{ccc}
$\begin{array}{c}\text { Lapisa } \\
\mathbf{n}\end{array}$ & $\begin{array}{c}\text { Resistivitas } \\
(\mathbf{O h m . m})\end{array}$ & $\begin{array}{c}\text { Ketebalan } \\
(\mathbf{m})\end{array}$ \\
\hline 1 & 698,5 & 300 \\
\hline 2 & 1498,08 & 29,5 \\
\hline 3 & 4500 & 200 \\
\hline 4 & 5000 & 14.98 \\
\hline 5 & - & 20 \\
\hline
\end{tabular}

\section{KESIMPULAN}

Penerapan metoda algoritma genetik pada pemodelan MT 1-D dan pemilihan parameterparameter GA memberikan hasil yang baik pada model tiga lapis dan lima lapis. Dengan kata lain, metoda GA mampu menghasilkan kembali model sintetik bahkan untuk model bumi lebih dari tiga lapis, dalam hali ini model bumi lima lapis. Namun pada inversi lima lapis untuk model sintetik-2 iterasi yang dibutuhkan untuk mencapai konvergen lebih lama bila dibandingkan dengan inversi tiga lapis yaitu 150. Hal ini disebabkan karena jumlah parameter model yang digunakan lebih banyak pada inversi lima lapis yaitu 9 
parameter model yaitu $\rho 1, \rho 2, \rho 3, \rho 4, \rho 5$ dan h1, h2, h3 serta h4. Sedangkan pada inversi tiga lapis pada model tiga lapis hanya menggunakan 5 parameter model yaitu $\rho 1, \rho 2$, $\rho 3$ dan h1 dan h2. Kurva average misfit dan fitness memiliki pola yang fluktuatif bila dibandingkan dengan best misfit dikarenakan misfit dan fitness yang diperoleh adalah misfit dan fitness rata-rata sedangkan best misfit adalah misfit yang terbaik dari setiap turunan yang dihasilkan dari generasi ke generasi serta menunjukkan terjadinya proses pencarian solusi optimum dengan pencarian global untuk menghindari solusi terjebak kedalam minimum lokal bukan minimum global.

\section{DAFTAR PUSTAKA}

Coley, D.A., (1998), An Introduction to Genetic Algorithms for Scientists and Engineers, World Scientific, 22-26.

Goldberg, D.E., (1989), Genetic Algorithms in Search, Optimization and Machine Learning, Addison Wesley, 59-88.

Grandis, H., Syaripudin, A., (2001), Inversi Data Magnetotellurik 1-D Menggunakan Metoda Simulated Annealing, Kontribusi Fisika Indonesia, 12, 50-51.

Peréz-Florez, M.A., Schultz, A., (2002), Application of 2-D inversion with genetic algorithms to magnetotelluric data from geothermal areas, Earth Planets Space, 54, 607-616.

Tian, Y., Qian, J., Mei, F., (2005), Optimal Design of Matched Load by Immune Micro Genetic Algorithm, Progress In Electromagnetics Research Symposium, Hangzou, China, 101-104.

Ward, S.H., Hohmann, G.W., (1988), Electromagnetic theory for geophysical applications, In : Nabighian, M.N. (Ed.), Electromagnetic Methods in Applied Geophysics, Vol.1, Theory. Society of Exploration Geophysicist, Tulsa, Oklahoma, pp.131-312.

Zhdanov, M.S., Keller, G., (1998), The Geoelectrical Methods in Geophysical Exploration, 31, 261-346. 
